To appear in Z. Radman (ed.), Knowing without Thinking: The Background in Philosophy of Mind, Basingstoke: Palgrave.

\title{
1 Ground-Level Intelligence: Action-Oriented Representation and the Dynamics of the Background
}

\author{
Massimiliano Cappuccio and Michael Wheeler
}

\section{Introduction: the King's Routine}

Studies of embodied intelligence have often tended to focus on the essentially responsive aspects of bodily expertise (for example, catching a ball once it has been hit into the air). But skilled sportsmen and sportswomen, actors and actresses, dancers, orators, and other performers often execute ritual-like gestures or other fixed action routines as performanceoptimizing elements in their pre-performance preparations, especially when daunting or unfamiliar conditions are anticipated. For example, a recent movie (The King's Speech) and a book of memories (Logue and Conradi, 2010) have revealed that, just before broadcasting his historic announcement that the United Kingdom was entering the Second World War, King George VI furiously repeated certain tongue twisters in a resolute effort to overcome his relentless stutter. Such ritualized actions don't merely change the causal relations between performers and their physical environments (although this may well be part of their function); they provide performers with the practical scaffolds that summon more favourable contexts for 
their accomplishments, by uncovering viable landscapes for effective action rather than unassailable barricades of frightening obstacles. In other words, while the kinds of embodied skills that have occupied many recent theorists serve to attune behaviour to an actual context of activity, whether that context is favourable or not, preparatory embodied routines actively refer to certain potential (and thus non-actual) contexts of a favourable nature that those routines themselves help to bring about, indicating the possibilities of actions disclosed by the desired context. As we shall see, this sort of transformative event, which is exemplified by, but not confined to, the ritualized gestures and routines of skilled performers, is a regular occurrence in everyday skilled activity, not the crowning achievement of a few talented individuals; so the capacity in question belongs centrally to our ordinary suite of bodily skills. The theoretical ramifications of that embodied capacity are the topic of this paper.

Our ability to skillfully indicate and reconfigure contexts is intimately intertwined with the widely cited, but (we think) incompletely understood, phenomenon of the background. Following others, we take the background to be the implicit and plausibly endless chains of preconditions (bodily, attitudinal, social, cultural) that provide the context-dependent meaning and normative relevance conditions for any specific intelligent action. Consider, for example, the innumerable preconditions of this kind which are in play when an intelligent being walks into a BBC studio and recognizes it as the uncanny setting of an historically momentous, personally challenging, public speech. Our remarkable capacity to navigate the open-ended and shifting structure of a human life by way of the background is what Dreyfus (2008) calls 'background coping' or 'ground-level intelligence'. In what follows, we shall argue that the defiantly nonrepresentational conception of ground-level intelligence developed and defended by Dreyfus himself, and by others who share his general approach, is ultimately unable to do justice to the distinctive dynamics of background, precisely because that conception, at least partly as a consequence of 
its representation-shunning character, fails to encompass the particular, transformative, background-involving embodied capacity so strikingly illustrated by the King's routine.

\section{Absorbed Coping, the Background, and the Problem of Relevance}

According to one generic, orthodox view, traditionally dominant in areas such as cognitive science and artificial intelligence ( $\mathrm{Al}$ ), intelligent behaviour is internally mediated, in multiple and varied ways, by models of the world, specifications of pregiven goal-states, and/or problem-solving procedures based on stored rules and heuristics. This theoretical package call it cognitivism - is no longer mandatory, even in cognitive-scientific circles. One source of disquiet comes from a philosophical approach to intelligence that, in the hands of some thinkers, has recently and controversially been converted from a hostile brake on the ambitions of cognitive science into an emerging alternative conceptual framework within which cognitive science might be developed. (For some of the details of this transformation, see for instance

Kiverstein, forthcoming; Wheeler and Di Paolo, forthcoming.) First advanced by Dreyfus (for example, 1992, 2002a, 2002b), and then in various forms by, for example, Kelly $(2000,2002)$, Rietveld (2008, forthcoming) and Wheeler (2005, 2008, 2010; Cappuccio and Wheeler, 2010), the approach in question draws its inspiration from phenomenological thinkers such as Heidegger and Merleau-Ponty. In its most prominent form (to be placed under scrutiny here), the view takes everyday intelligent activity to be most revealingly characterized by a mode of engagement with environmental entities that Dreyfus (2002a) has dubbed 'absorbed coping', understood as the skillful and fluid adjustment of behaviour to context-dependent contingencies by way of a richly adaptive, direct (that is, unmediated by representations or any subject-object interface), situated sensitiveness to what is relevant. 
The notion of absorbed coping will be important in what follows, so it is worth pausing here to unpack it a little. The behaviour of an absorbed, coping agent, motivated to achieve his practical goals, is not regulated by any set of truth conditions attached to a pre-specified goalstate (that is, a description of the state of affairs in which a belief that some goal-state obtains would be true; cf. means-end analysis Al algorithms that produce plans for reducing the difference between the current state of the world and some explicitly represented goal-state). Rather, the behaviour of an absorbed, coping agent is regulated by that agent's capacity to sense intensities of deviations from a contextually determined optimal balance with her environment, coupled with her instinctive practical knowledge of how to adjust her behaviour to improve her performance and thus reduce her sense of being out of balance. With absorbed coping identified as a kind of zone of expert performance, skill acquisition and direct sensitiveness to contextual relevance may be seen as developing together and as implicating each other, since coming to have a mature performative competence for a certain action means becoming able to recognize what situations afford it appropriately, and distinguishing the finegrained articulation of a situation means knowing how to navigate it competently (Dreyfus, 2002a).

One might articulate this picture further by identifying the absorbed coper's direct sensitivity to relevance - his unmediated sense of being in or out of balance with her environment - as indicating the property of thrownness (Heidegger, 1996). As thrown, the absorbed coper always finds himself in a world that matters to him in some way or another. This always-already-meaningful world into which he is thrown is encountered fundamentally in terms of practical dispositions towards context-dependent affordances (possibilities for action presented by the environment). But, crucially, the contentful structure (or significance) of this world is neither fully articulated within the practical knowledge that enables the coper to negotiate situations, nor is it fully articulable in some ideal theoretical register. This is because 
that structure encompasses a vast and indeterminate web of implicit preconditions for sense making, "an unexplicated horizon" or background, providing "the vantage point from out of which" every experience matters to one in certain way (Taylor 1993, p. 325). As we shall understand this horizonal background, it contains every interwoven element of our adaptive know-how (whether bodily, attitudinal, social or cultural), that is presupposed by our concrete practical engagements. The background is thus itself a body of adaptive know-how, although one which is implicitly presupposed by, rather than on open display in, everyday patterns of skilled activity. This suggests that our epistemic relationship with the background (our familiarity with, and capacity to smoothly navigate, its unarticulated patterns of significance) is itself a kind of coping, hence Dreyfus's (2008) term background coping. Moreover, since the background is, in effect, a transcendental condition for absorbed coping, it constitutes a deep-structural feature of skilled expert performance; so background coping constitutes our ground-level intelligence (see again Dreyfus, 2008).

If we view intelligent behaviour in the light of its thrownness, we can offer a compelling diagnosis of why cognitivist $\mathrm{Al}$, as identified above, has struggled to provide any general solution to the so-called frame problem (for this claim, see Dreyfus 1992, 2008; for discussion, see Wheeler 2005). Here, the frame problem is to be interpreted in the widest possible sense, as the problem of building a naturalistically discharged system (for example, a computational machine) that can process information and produce behaviour in a manner that is fluidly and flexibly sensitive to context-dependent relevance. In this general form, the frame problem might simply be re-named the problem of relevance. Here is how the problem manifests itself. Faced with the challenge of determining which of its behaviour-generating rules and representations are relevant in the present context, the cognitivist agent might naturally deploy second-order rules and representations that determine first-order contextual relevance. But this strategy can succeed only in pushing the issue of relevance one stage back, for the system then needs to 
decide which of its stored heuristics or potentially context-specifying representations are currently relevant, a challenge which requires a further, higher-order set of heuristics or representations, and so on. Put another way, to the extent that cognitivist $\mathrm{Al}$ persists in attempting to capture the background (the preconditions of our context-situated intelligence) in terms of explicit representations and rules, it runs headlong into an infinite regress of contextspecifying structures. Once we adopt the perspective of thrownness, however, the conditions that generate this sort of infinite regress are never established, because appropriate behaviour selection and modification are rooted in a nonrepresentational direct coupling between agent and environment which already embodies sufficient sensitivity to relevance. In particular, because the normative preconditions of an action are implicitly embedded in the context that the agent inhabits as a practical scenario - as features of that agent's background - they don't need to be scrutinized as aspects of a problem to be decoded and solved.

At this point things get more complicated, for it seems to us that there are two different dimensions to the problem of relevance. First there is an intra-context problem, which challenges us to say how a naturalistically discharged system is able to achieve appropriate, flexible and fluid action within a context. Then there is an inter-context problem, which challenges us to say how a naturalistically discharged system is able to flexibly and fluidly switch between an open-ended sequence of contexts in a relevance-sensitive manner (Wheeler 2008, 2010). If this distinction between an intra-context and an inter-context problem of relevance is indeed genuine (criticisms of the distinction will be considered later), an intriguing question suggests itself: are the nonrepresentational processes that we have met so far under the banner of Dreyfusian ground-level intelligence sufficient to account not only for our withincontext sensitivity to relevance, but also for our capacity for relevance-sensitive, open-ended context-switching? It is to this question that we shall now turn. 


\section{Solicitation and Summoning}

If we add a little more detail to the picture of ground-level intelligence sketched so far, an affirmative answer to our question comes into view. The key here is an application of MerleauPonty's (1962) notion of the intentional arc, according to which skills are not internally represented, but are realized as contextually situated solicitations by one's environment that tend to become more fine grained with experience (see Dreyfus 2008, 340). Thus, as Gallagher (2008) explains, when poised to engage in the action of climbing a mountain, the skilled climber does not build an inner representation of the mountain and infer from that plus additionally represented knowledge of her own abilities that it is climbable by her. Rather, from a certain distance, in particular visual conditions, the mountain 'simply' looks climbable to her. Her climbing know-how is 'sedimented' in how the mountain looks to her and thus may solicit the action of climbing from her. Clarifying this idea further, Rietveld (forthcoming) usefully draws a distinction between different kinds of affordance. Given a specific situation, some affordances are mere possibilities for action, where 'mere' signals the fact that although the agent could respond to them in some way, such a response would be contextually inappropriate. In the same situation, however, some affordances, precisely because they are either directly contextually relevant to the task at hand, or have proved to be relevant in similar situations in the past, prime us for action and thus, as Rietveld (forthcoming) puts it, render us ready to act in appropriate ways by being bodily potentiating. It is affordances of the latter kind that are identified by Rietveld as Merleau-Pontian solicitations, divided into figure solicitations and ground solicitations. Figure solicitations are those with which we are actively concerned. Ground solicitations, by contrast, are those with which we are not currently concerned, but for which we are currently potentiated, and which are thus poised to summon us to act. (see Rietveld forthcoming). According to this phenomenological analysis, the background structures of ground solicitations, together with the process of summoning that those structures support, are the nonrepresentational conditions that explain our capacity for adaptive context-switching. 
It is important to note that the distinction between figure and ground solicitations should be conceived not in terms of two fundamentally separate kinds of element governed by distinct proprietary mechanisms, but in terms of different perspectival depths within the same overall structure of significance. These perspectival depths correspond respectively to the proximal concerns of an occurrent practical context and the potential retrieval of relevant sense-making elements from an entire life and history (an immanent and finite condition of being-in-the-world; Heidegger 1996). In harmony with the idea that intelligent behaviour involves a complex but ultimately continuous landscape of varying perspectival depths, Dreyfus (2008) argues that it is at root the same practical, competent disposition to maintain a dynamical balance with contextual circumstances that underlies within-context absorbed coping and cross-contextual summoning, and that this competence is materially implemented at the subpersonal level by the same set of complex, dynamical, nonrepresentational structures and processes. To provide an example of such subpersonal structures and processes, Dreyfus calls on the neurodynamical framework developed by Freeman (2000), in which the brain is conceptualized as a nonrepresentational dynamical system primed by past experience to actively pick up and enrich significance. The constantly shifting attractor landscape of such a system physically grounds Merleau-Ponty's intentional arc, by causally explaining how newly encountered significances may interact with existing patterns of inner organization to create new global structures for interpreting and responding to stimuli.

Taken to the limit, the line of thought that we have been laying out generates scepticism about the very distinction between intra-context and inter-context versions of the problem of relevance. Thus Rietveld (forthcoming) argues that sensitivity to within-context relevance essentially coincides with the broader sensitivity to global relevance that guides nonrepresentational background coping. If context-specific activity were genuinely encapsulated 
(that is, if it relied only on segregated portions of the background), then our responses to local contingencies, even if successful, would be at constant risk of neglecting the background on which their broader appropriateness depends. Rietveld illustrates this risk by drawing an analogy between contextually encapsulated relevance-sensitivity and a neuropsychological pathology called 'utilization behaviour'. Patients with this disorder are excessively sensitive to the local affordances provided by the immediate environment, and suffer from an inability to discriminate between appropriate and inappropriate behavioural responses (Lhermitte, 1986, p. 342). As a result, contextually inappropriate actions are not inhibited, even though broader background knowledge should discourage them. For example, a patient exhibiting utilization behaviour may start compulsively making the bed that he or she sees before her, even if this bed is in someone else's house. Rietveld imputes such behaviour to a disruption of the normal tendency to situate the local context of action within its holistic background, a tendency that he calls sensitivity to 'real relevance'. In his view, this impairment in sensitivity to real relevance reflects what would happen in normal subjects if context-specific activity were encapsulated.

For Rietveld, then, ground-level intelligence underwrites a behavioural profile in which solicitation makes sense only where there is an intrinsic possibility of summoning. This, he concludes, destabilizes the distinction between intra-context and inter-context sensitivity to relevance. The point might be put like this: if the preconditions of all skills, including the most specialized ones, are part of an holistic, unrepresentable "background sense of reality [...], something we possess in - that is inseparable from - our actual dealings with things" (Taylor, 1993, p. 327), then arguably there is no precise boundary separating the context-specific forms of coping from background coping, but only local ways for the latter to be revealed within the former. To return to our opening example, the context-specific task of speaking on national radio wouldn't have been such a tremendous ordeal for George VI, if that task wasn't interpenetrated by a range of background conditions, including some excruciating personal circumstances, 
institutional and familial expectations, the fact that he had recently become King in a very dramatic political contingency, and so on.

Rietveld proceeds to deny the target distinction on additional, neurofunctional grounds. Here he targets previous work by Wheeler $(2008,2010)$, in which it is argued that the intracontext problem of relevance may be neutralized by a sub-class of encapsulated mechanisms that he (Wheeler) calls special-purpose adaptive couplings (SPACs). The precise details of Wheeler's analysis and argument need not concern us here (although a little more detail is given below, during the discussion of Mataric's robot, Toto), but the general thought in play is that because SPACs become activated correctly only in the presence of the right, contextually relevant input, the intra-context problem of relevance never arises for them. Rietveld suggests that the best candidates for neural SPACs are certain context-specific installed routines present in the lateral premotor areas of the brain (routines that involve mirror neurons, canonical neurons, and other action-specific families of motor neurons). But, he observes, "preafference shows that the triggering of SPACs $[\ldots]$ presupposes the proper functioning of the medial frontal system that determines the sensitivity of the sensory system" and "tunes it to respond to what is currently significant to the individual" (Rietveld, forthcoming, p. 23; cf. Dreyfus, 2008, p. 350). Importantly, this modulation of the system's sensitivity is something that normally happens before the stimulus is picked up. So the proper functioning of the premotor system that instantiates SPACs is dependent on the prior activity of the medial premotor system, the system that, according to Rietveld, orients the sensory expectations of the agent, tuning her general sensitivity to the overall context in which she is situated. Once again, then, the distinction between intra-context and inter-context sensitivity to relevance is placed under threat.

We introduced this section by wondering whether the kind of nonrepresentational account of ground-level intelligence advocated by Dreyfus has the resources to account for all 
forms of sensitivity to relevance. By now it may seem that a compelling affirmative answer has been given to that question, and that the boot has been transferred to the other foot. In other words, rather than worrying about the scope of the nonrepresentational account of background coping, it seems we should be asking whether it is possible for background coping ever to engage representations. So let's ask that question.

\section{Ground-Level Representations}

At this point we need to back up slightly. We wish to propose two principles pertaining to the nature of the background, principles that, we think, any adequate account of the background would need to respect. The first, strongly suggested by our foregoing discussion of Dreyfus and Rietveld, is what we shall call the principle of unity. This states that the background cannot be decomposed into self-sufficient, encapsulated parts without sacrificing the holism that characterizes its transcendence. The second is what we shall call the principle of mutuality. The justification for this principle comes from Merleau-Ponty's (1962, p. 159) pregnant observation that "movement and background are, in fact, only artificially separated stages of a unique totality". We take this observation to imply that background coping and context-specific coping enjoy a background-foreground relationship (recall the discussion of different perspectival depths in a single landscape of significance; see also Cappuccio and Wheeler, 2010), but also, and crucially, that the relationship in question is one in which the two modes of coping, conceptualized (somewhat artificially, as Merleau-Ponty points out) as separate stages in the process of sense-making, are able to dynamically shape each other. The principles of unity and mutuality enable us to re-ask the question of whether or not there exist ground-level representations. The principle of unity suggests that background coping may discriminate between contexts by somehow representing the criteria for such discrimination, if and only if some contingent configurations of the background could act as representations of the background itself, without this implying a decomposition of the background into self-sufficient, 
encapsulated parts. The principle of mutuality suggests that the nonrepresentationalist account of ground-level intelligence advocated by Dreyfus and Rietveld is unable to do justice to the complex and subtle dynamics of the background. It might seem as if this claim must be wrong, since it might seem that the Dreyfus-Rietveld view embraces the principle of mutuality. In what follows, however, we shall argue that that view encompasses an overly restrictive, essentially static account of the relationship between context-specific coping and background coping, an account that supports a relation of one-way dependence, but not one of dynamic codependence. But if that is right, then the possibility that there exist ground-level representations is back on the agenda. The challenge would then be to show that there are situations which are consistent with - or perhaps, to raise the bar further, suggested by - the principle of mutuality, in which the presence of ground-level representations is not merely possible, but to be expected. We think that this challenge too can be met, and in its more demanding form.

To put us on the right road, here is an opening thought. From a Heideggerian phenomenological perspective, there is every reason to think that there exists a mode of context-specific coping that is representational in form. The key here is a way of encountering entities that Heidegger (1996) calls un-readiness-to-hand. This is in contrast with readiness-tohand (the transparency of equipmental entities in hitch-free use which is correlated with nonrepresentational absorbed coping) and presence-at-hand (the explicit consciousness of entities as full-blown objects which is correlated with the kind of fully representational, decontextualized reasoning prioritized by the cognitivist picture). Un-readiness-to-hand emerges paradigmatically when skilled practical activity is disturbed by broken or malfunctioning equipment, discovered-to-be-missing equipment, or in-the-way equipment, although, as Cappuccio and Wheeler (2010) have stressed, un-readiness-to-hand does not need to be the result of some actual disturbance to a pre-existing flow of absorbed coping, but may be established by an attitude on the part of the agent. When encountered as un-ready-to-hand, 
entities typically solicit the agent to temporarily monitor and plan his actions, in order to solve context-specific practical problems posed by the environment. For instance, if I am on the way to work, a broken watch is encountered by me not as a lump of metal of measurable mass (that is, as a present-at-hand object removed from the range of my practical concerns), but as a faulty timekeeper, a damaged tool that constitutes a hindrance to my train-catching activity. It thus solicits certain remedial, context-dependent, problem-solving actions (for example, the use of alternative time-keeping resources, planning a visit to a watchmaker).

Heidegger's analysis suggests further that the kind of practical problem solving distinctive of un-readiness-to-hand involves representational states (Wheeler, 2005, 2008, 2010). Crucially, however, these are not the full-blooded cognitivist representations that plausibly mediate epistemic access to the present-at-hand. When revealed as present-at-hand, an entity will be experienced in terms of properties that are action-neutral, specifiable without essential reference to the representing agent, and context-independent. By contrast, when revealed as un-ready-to-hand, an entity will be represented in terms of properties that are action-specific, egocentric and dependent on a particular context of activity. - So, for example, the online, task-engaged navigator may represent the external environment by way of an egocentrically defined space in which obstacles appear only as regions to be avoided, positioned in terms of roughly specified bearings relative to her own body. The character of the kinds of representations distinctive of un-readiness-to-hand is an issue to which we shall return. For the moment, the key point is that, although practical problem solving in the domain of the un-ready-to-hand is not absorbed coping (by hypothesis, absorbed coping has been disturbed), it nevertheless remains a form of context-specific coping (since it is paradigmatically a skilled adaptive process oriented towards re-establishing a dynamical balance with a specific extant situation). From now on, then, we shall use the term skilled coping as an overarching term 
covering both forms of context-specific coping. Using this terminology, the point on the table right now is that skilled coping may come in nonrepresentational and representational forms.

Perhaps surprisingly, Dreyfus agrees that, in cases of un-readiness-to-hand, skilled coping within specific contexts occurs in a representational modality. He argues, however, that "all coping, including unready-to-hand coping, takes place on the background of [a] basic nonrepresentational, holistic, absorbed, kind of intentionality, which Heidegger calls being-inthe-world" (Dreyfus 2008, 345-6). In other words, skilled coping, whether representational or not, is derivative on background coping, which, by Dreyfusian lights, is necessarily nonrepresentational. Thus although representations may figure in certain forms of intelligent behaviour within the more fundamental condition of thrownness (that is, provided that background coping is already in place), they cannot figure in the ground-level process of background coping itself. On this model, then, the dependency relation between background coping and skilled coping is unidirectional and bottom-up. And that's why the Dreyfusian model, as built on by Rietveld, ultimately falls short of being a satisfying account of the background. Its commitment to a one-way dependency relation between skilled coping and background coping collides head-on with the Merleau-Pontian prerequisite of a strict dynamic co-constitution between an action and its background; in other words, it flouts the principle of mutuality.

So now what happens if we wholeheartedly pursue a model in which background coping and skilled coping are genuinely and dynamically co-dependent? To set the scene, let's return once more to our opening example. It is true both that George $\mathrm{VI}$ was coping with his background when he forced himself to give his speech on the national radio, and that his oration constituted an instance of skilled coping directed at producing a certain performance. Now, on the nonrepresentational account of ground-level intelligence, some aspects of this story remain decidedly unexplained. What really did push King George VI to give his speech, in spite of his 
debilitating stutter, taking on an institutional duty that intimidated him and that his brother had declined not long before? It seems difficult to claim that his decision to confront the local context of that public announcement was fluidly coupled with, and unproblematically derived from his personal and political history (and thus from his background coping), as the emotional tone of the situation seemed strongly to discourage that decision; so much so, in fact, that even his personal identity and institutional function, and not just the contingent circumstances of the speech, could be seen as an anguishing state of affairs to be avoided (more on Angst below). After all, George had always thought of himself as a marine officer, and was totally unprepared to be crowned until a few weeks earlier. We can infer from this that neither the King's existential background nor the local context of his action established preconditions or affordances that positively summoned or solicited him to accomplish his duty. In truth, both the global background and the local context hindered his action so strongly that he had to suspend his direct coupling with them, and actively create a more favourable context into which to transfer his performance. This shift could be achieved only through a resolute effort on the part of the King to become aware of, and to change, the conditions of his contextual situation, and not through a process in which he unreflectively accommodated himself to those conditions. Hence the disclosive and transformative function of the King's embodied preparatory routines, his furiously repeated tongue twisters. Some skilled embodied practices (like preparatory gestures), then, don't merely achieve an appropriate response to the actual contextual opportunities of action, but rather address the context itself as a problem, in order to reconfigure it and to disclose new opportunities for action.

This capacity to reconfigure the background, in order to achieve local context-creation, is an idea that bubbles away tantalizingly, alongside Dreyfusian summoning, in Sutton's (2007) compelling recent analysis of expert batting in cricket. Sutton observes that certain “individualized 'pre-ball routines' as the batsman prepares and takes guard act [...] as a 
transportable sequence of consistent and comfortable signs which prepare the mindful body for action" (p. 774; more later on this crucial idea of embodied routines as signs). These preparatory embodied routines are then linked, in a way that is suggestive of context-creation, to the ability of expert batsmen to reset their response profiles at key moments in the game.

When the match situation is changing rapidly and continually - over the crucial dying overs of a decisive one-day game, for example - good players will be constantly resetting their response repertoire in ways which may have been discussed or partly planned out in advance, either deliberately or simply as the result of the sedimented history of relevant experience. This doesn't mean deciding in advance that only one stroke is allowable "no matter what," but rather altering the probabilities of attempting certain shots to certain ranges of possible deliveries [...] One successful case was when, during the oneday internationals before the 2005 Ashes series, Andrew Strauss set himself more than once to get way across to the offside, outside the line of good-length balls from Jason Gillespie and use the pace to lift them over fine leg, a shot unthinkable in less audacious circumstances. (Sutton, 2007, p.775)

At this point a clarification (or perhaps a complication) is in order. Although further analysis is required, it is arguable that our examples of preparatory embodied routines do not reward the kind of 'voluntaristic' interpretation that one might naturally find most tempting. Indeed, in our view, there is reason to be suspicious of any claim that the reconfiguration of King George VI's background was the outcome of an absolutely free choice on his part, a choice in which he employed some sort of latent 'inner power' against the external circumstances. Heidegger (1996, p. 176) warns us that to interpret the phenomena of resoluteness and deliberation in these sorts of voluntaristic terms would be to miss the fundamental fact that there cannot be any decision that is not always already decided by its background preconditions. This Heideggerian principle, it seems, should apply to those decisions that concern the background 
itself. After all, one might see King George Vl's transformation of his predicament as itself situated within an acceptance of certain broader circumstances, meaning that the decision to deploy specific preparatory embodied routines was the only possibility disclosed to the King at that time, the only thing he could do to respond to the dramatic call of the situation. So decisions cannot be abstracted from their background altogether. Nevertheless, that doesn't alter the fact that some decisions must be taken, those that serve to abstract the agent's behaviour away from certain extant configurations of the background while producing new specific configurations. As we have seen, the King's speech simply couldn't have been delivered, if he hadn't used his preparatory embodied routines to gather his resolute decision, in part as a way of ignoring those context-specific solicitations that would have positively hindered his skilled performance.

Preparatory embodied routines enable a special kind of context-switching in which an appropriate set of action-soliciting conditions is called forth actively by those very routines. Context-switching is here not a response to shifting environmental circumstances, but an agentdriven intelligent strategy for adaptively structuring behaviour. Our proposal is that the functioning of such routines needs to be understood as one which is representational in form. An immediate reason for thinking that representational language is appropriate here draws on our earlier Heideggerian claim that un-readiness-to-hand (the disruption of absorbed coping) ushers in a representational mode of agent-environment engagement, because it opens up a problem-solving cognitive distance between agent and environment. It seems that preparatory embodied routines assume the same kind of problem-solving cognitive distance between agent and environment as is operative in the domain of un-readiness-to-hand, suggesting an extension of the representation-involving explanatory template from the latter to the former. Turning this suggestive analogy into a compelling explanatory perspective requires some additional conceptual machinery. 


\section{Signs as Action-Oriented Representations}

There are situations in which intelligent behaviour requires us to deal with the whole context of our current coping activity. This happens when we need to recall the whole network of practical preconditions that define our present possibilities of action, possibly to contrast them with other, non-actual possibilities that are connected to them. In Heidegger's phenomenological analysis, this experience is initiated by Signs.

In the theoretical sense that matters here, the class of Signs is not limited to graphic signs or conventional means of communication, but potentially includes any situational element (event, state, process, thing ...). When revealed as Signs, situational elements make us aware of our context and delineate its normative boundaries. A "sign is something ontically ready-tohand which is not just this particular equipment, but functions as something that indicates the ontological structure of readiness-to-hand, referral-totality and worldhood" (Heidegger, 1996, p. 82). Any situational element can become a Sign, just as soon as it emerges out of the background of our skilled coping activity and starts to orient our attention towards those background conditions themselves. For example, malfunctioning or unfamiliar pieces of equipment are likely to become Signs of the problematic situation in which they show up, introducing un-ready-to-hand interactions. Thus a road sign informing the skilled driver of a detour announces that her absorbed coping with the road is interrupted, and indicates that she must withdraw from her current activity of automatic driving, possibly switching to an alternative, reflective modality of driving, in order to follow or find an alternative route home. For a stuttering orator who is on the threshold of giving an important speech, the smallest hesitation in pronouncing a single syllable may become a Sign of his challenging situation. As a Sign, his hesitation reminds him that his oratorical task is risky, that he must focus carefully on the training received, that he cannot fail for the sake of his personal, familial, and institutional duties. 
This attention combines with a sudden awareness of many preconditions (about his present situation, past training, future historical consequences) that were buried in the background of his oratorical activity until the instant that he hesitated on that syllable. Even when coping proceeds smoothly, ready-to-hand pieces of equipment may morph into Signs, disclosing to our attention that the whole context of action, rather than just this or that piece of equipment, matters to us and constrains our conduct. Thus a delicious smell coming from the oven is a Sign reminding us of our current activity of cooking and making us aware that it is time either to check the progress of our almost baked cake or to switch to the context of preparing the table for dinner. Signs thus operate in ready-to-hand and to un-ready-to-hand scenarios. The main difference is that while, in the former kind of scenario, Signs create the possibility of reflecting on one's absorbed coping (including the possibility of disrupting that coping) as a successful outcome of the coping process itself, in the latter kind of scenario, in which an interruption to absorbed coping has already happened, Signs more directly establish the shape of the appropriate reflective response.

So, by standing out from their inconspicuous surroundings, Signs call the skilled agent to pay attention to the circumstances, the preconditions, and the goals of her activity. So conceived, Signs often allow us to adjust our behaviour to the present context of action. Equally, however, because of that same signs standing-out, background-disclosing function, Signs may provide the instigating means by which adaptive context-switching - whether reactive or proactive in nature - may occur. It is at this point that it becomes illuminating to conceptualize preparatory embodied routines - routines whose function is precisely to reconfigure the background, in order to transform the context for action - as a special sub-class of Signs. This Heideggerian gloss, we think, allows us to appreciate the full scope and importance of Sutton's (2007, p.774) cricket-related remark that "individualized 'pre-ball routines' as the batsman 
prepares and takes guard act [...] as a transportable sequence of consistent and comfortable signs which prepare the mindful body for action" (emphasis added).

The next piece in the theoretical jigsaw we are building is to conceptualize Signs, and thus preparatory embodied routines, as representations. What this would establish is that, contra Dreyfus, context-switching may be enabled and driven by representational structures. Of course, Dreyfus holds that representations cannot solve the problem of relevance. Indeed, he goes further, by suggesting that, from a Heideggerian phenomenological perspective, the problem of relevance is revealed, at least partly, to be an artefact of representationalism. As he puts it, 'for Heidegger, all representational accounts are part of the problem' (Dreyfus 2008, p. 358). If Dreyfus is right, our attempt here to interpret the relevance-sensitive structures that are Signs, and thus to interpret preparatory embodied routines, in representational terms is doomed to failure. But is it right? To resist Dreyfus's antirepresentational scepticism, we need to remind ourselves that representations come in more than one conceptual flavour. As we have seen, in the fully decontextualized mode of presence-at-hand, representations in experience will encode properties that are essentially action-neutral, specifiable without any necessary reference to the representing agent, and context-independent. A map in a Cartesian co-ordinate system would be an example of a present-at-hand representation. In the mode of un-readiness-to-hand, however, entities will be represented in experience in terms of properties that are actionspecific, egocentric and intrinsically embedded in a particular context of activity. Representations with this profile have been dubbed action-oriented representations (henceforth AORs; for further discussion, see for instance Wheeler 2005).

It will be useful to deepen our appreciation of the nature of AORs, by investigating the subpersonal, mechanistic counterparts of the phenomenologically identified cases on which we have concentrated so far. A seminal example of subpersonal AORs is provided by Mataric's 
sonar-driven mobile robot Toto (Mataric, 1991). Toto wanders around its office environment following walls and avoiding obstacles. As it proceeds it constructs an internal map encoded in terms of patterns of sensorimotor activity. For example, if Toto keeps detecting proximally located objects on its right hand side, while its compass bearing remains unchanged, then a 'right-wall' is encoded in the subagential map, not as some objective entity, but in terms of the robot's sensorimotor 'experience' at the time. These structured sensorimotor 'experiences' (Toto's landmarks) are stored as connected nodes in a distributed graph, and this record of the robot's own sensorimotor history constitutes its subpersonal map of the spatial environment. Toto is then able to navigate its way around using paths encoded as sequences of past, current, and expected sensorimotor 'experiences'.

Toto's maps thus exhibit the range of inter-related properties that were previously disclosed by a phenomenological analysis of un-readiness-to-hand, and which are distinctive of AORs. They are action-specific, in that they are tailored to the job of producing the specific behaviour required. They are egocentric, in that they encode the environment in terms of the robot's own history of sensorimotor 'experiences'. And they are intrinsically context-dependent, in that because those maps are embedded in the kind of domain-dependent, task-specific mechanisms that we earlier identified as SPACs (meaning that they wouldn't be any good for working out things like the objective distance to the snack bar), Toto never confronts the problem of selecting, out of a vast sea of potentially available spatial information that could have been retrieved and internally stored, the subset of such data relevant to the navigational context in which it operates. Another way of explicating this final property is as the reason why Toto never confronts the frame problem, a reason which turns directly on the conceptual profile of AORs. 
As a result of the operative profile just described, AORs are what might be called minimally representational in character. Rather than determinately specifying some detailed objective content (knowledge-that), AORs indicate an open-ended set of possible actions (a kind of under-specified knowledge-how), just like the detour sign that vaguely suggests the many directions that, given one's practical knowledge, one might take to drive home. Mention of the detour sign suggests a crucial observation. If we permit ourselves to interpret egocentricity more generally as a kind of perspectival deictic indication, Signs may be counted as AORs. As AORs, Signs indicate the different possibilities of coping that essentially define the current context or, via the background, a range of potentially associated contexts. Signs are not present-at-hand representations, because their referential function is not action-neutral or context-independent. Rather, their function is essentially action-orienting and context-specific, warning us that something must be done in a certain situation (for example, 'take the detour'). Given their minimally representational status, however, the precise form of this 'something that must be done' will be determined in detail by the trajectory of our competent engagement in the world.

A Sign, understood as an AOR, will determine a standpoint that is disclosed from within the background, but from which we relate to that background, allowing us to redirect our attention to access different depths or levels of coping, and thereby alter the relevance of various action-shaping preconditions. At any moment, some background conditions will matter more than others, and Signs move us from one perspectival angle to another, actively transforming the potential availability of different contexts of actions, and not merely the potential availability of alternative actions within the same context. Tongue twisters and other preparatory rituals are thus best interpreted as Signs that a performer, under the pressure of unfamiliar or problematic contingencies, deploys as a useful scaffold to change his dispositions towards the immediate contingencies, not only to better recognize the available affordances (he 
is already trained and ready to deal with the physical environment), but to establish a more appropriate perspective of self-interpretation in the light of a different configuration of his background. To see the environment as a familiar scenario for our actions requires recognizing it as compatible with certain background motivations, expectations and intentions that Signs prioritize in place of others that are debilitating or disruptive. We have seen that preparatory embodied routines, like Signs in general, enable us to manipulate the background preconditions and criteria that determine relevance, from within the current context. And since Signs are AORs, we can conclude that our capacity to navigate the background - our ground-level intelligence - is sometimes contingent upon the availability of minimal representations and is actively shaped by those structures.

The role that we have found for ground-level minimal representations might seem to contravene the principle of unity. The principle of unity would indeed be violated if the position we have sketched required the background to be divisible into encapsulated components, but the fact that the background can be articulated in different ways (that is, the fact that we can distinguish different modes or configurations of the global preconditions of one's situated sense of reality) doesn't imply encapsulation in any strict sense. If some forms of representation can in truth produce articulation without encapsulation, they will remain consistent with the holistic unity of the background. Our account keeps intact the unity of the background, by combining it with the idea that the background is accessed and manipulated perspectivally, from distinct angles. Each of these angles indicates a certain global reconfiguration of the totality of the background, which is however never exhaustively represented by any of these indications. Indeed, if a part or portion of the background, configured in representational form, attempted to encode the totality of the background, this would lead to an infinite regress (like an encyclopedia containing itself and its full description); but this regress is never established, if we assume that a local representational configuration of the background provides only an indication of some 
possible way of accessing the totality of the background (like an encyclopedia containing the index of its own chapters and contents). AORs (including Signs and thus preparatory embodied routines) indicate how to inhabit the background strategically; they do not attempt to build a complete model of the background. If this is right, and if such representation-driven strategic inhabitings provide the basis for events such as fluid context-switching, then minimally representational processes are indeed at the heart of the ground-level intelligence.

\section{5. 'Angst' and the Problem of Relevance}

As we have seen, Signs ordinarily prompt an agent to stand before this or that context of action. However, a particular experience that Heidegger calls 'Angst' allows an agent to stand apart from the totality of all the possible contexts in which she can act, intuiting the extreme edge that globally delimits her possibilities as a thrown individual. "Angst provides the phenomenal basis for explicitly grasping the primordial totality of being of Da-sein" (Heidegger, 1996, p. 176). Despite this explicit grasping of the totality of what is intelligible, Angst remains a phenomenon that occurs to situated agents within the world, not as a de-worlded 'view-fromnowhere', but as an immanent mode of attunement within the world that discloses the world as world. Intriguingly, a link may be forged between Angst and the problem of relevance.

To bring this link into view, we can begin by noting that although Angst can be announced by Signs, Signs cannot actually indicate the object or objects of Angst. That is because Angst has no object, or at least no definite one. Imagine that, while the preoccupied George VI is preparing himself to give a speech, he glimpses the austere gaze of an ancestor in an old painting, or sees a blinking light on the microphone watching him like a malevolent red eye, or hears his own voice hesitating on a certain syllable. These Signs, harmless in themselves, may disrupt his attention and fill his heart with vague senses of discomfort, apprehension and finally anxiety. The possibility of a complete failure looms, a possibility that 
shakes his confidence in his social skills, his political determination, and his historical mission. What this example indicates is that, in certain situations, even the most innocuous Signs can unearth such profound layers of the background, that the agent is shaken by deeper and deeper degrees of uncertainty. This uncertainty impairs, rather than facilitates, his capability to recommence a fluid process of coping. In this spiral of growing anxiety, not only the agent's acquaintance with this or that situation, but his whole sense of reality, his sense of being-in-theworld, is eventually challenged by questions such as: 'why am I here?', 'what is the real meaning of my actions?', 'what am I supposed to do now?', and so on. Manifested by a feeling of uncanniness, Angst doesn't have a precise object but expresses a wrenching of the agent from her meaning-giving background. Heidegger (1996, p.175) describes this phenomenon as a "not-being-at-home", the disorienting experience of being confronted by a meaningless world that appears alien and unintelligible.

Through Angst we encounter the fact that all the possible ways things usually matter to us depend on our situated perspectives in thrownness. But since it is in thrownness itself that is exposed by Angst, all our absorbed coping activities are revealed as devoid of intrinsic meaning. Those coping activities are now being observed from the perspective of our fundamentally precarious, ultimately ungrounded existential situation. As a consequence, even if all our competences are still in place, our ability to use them stops mattering to us. Our skilled coping becomes the "merely occurrent" (Heidegger, 1996, p.103) object of an anxious contemplation that disconnects affordances from the responses that they habitually summon in us. Thus "the totality of relevance discovered within the world of things at hand and objectively present is completely without importance. It collapses. The world has the character of complete insignificance" (Heidegger, 1996, p. 174). 
Crucially, the 'knowledge' gained through Angst never amounts in itself to a complete, fully-representational depiction of the background. Rather, the alienation that Angst introduces engages a restless interrogation on the part of the agent regarding the meaning of things. The questions that he poses to himself about this meaning cannot find a theoretical answer, because any such answer would presuppose the world that Angst had made meaningless. So, even if that question originates fundamentally from the background of that meaning, the very fact that the question is formulated in Angst makes the meaning of the background indiscernible. Although it is clear that the knowledge of the background revealed by Angst is not fully-representational, it seems plausible that it must be at least minimally representational, as it clearly produces a modulation of the background by adopting an explicit perspective within the background, assuming the dynamic co-molding of cognitive distance and skilled action that is typical of AORs and the kind of troubled coping regime that may be introduced by Signs, although this attunement with the background is of a very strange, uncanny nature. Crucially, for Heidegger, the minimally representational phenomenon of Angst precedes - ontologically, if not chronologically - even the possibilities of our skilled coping. As he puts it: "Tranquillized, familiar being-in-the-world is a mode of the uncanniness of Da-sein, not the other way around. Notbeing-at-home must be conceived existentially and ontologically as the more primordial phenomenon. And only because Angst always already latently determines being-in-the-world, can being-in-the-world" (p. 177).

Conceived as a fundamental structure of human life, Angst provides a new perspective on the frame problem. Structurally destined to care, and constitutively exposed to the possibility of the total loss of meaning through Angst, human beings seem realistically open to something tantalizingly close in form to the inter-context frame problem that affects cognitivist Al. Seduced by the dreadful Signs that lead her to withdraw from her context, the agent experiences a more and more dramatic loss of the sense of mattering, a loss that paralyzes her responsiveness to 
the circumstances and make her aware of the necessity to deliberate, even if no stable foundation for deliberation is available. The endless series of questions that the agent is driven to ask about her own being, as she endeavours to delineate contextual meaning (what matters) is analogous to the infinite regress of meaning-targeting structures that are indicative of the frame problem. The difference is that, in the case of humans, the Angst driven 'frame problem' derives from a contingent suspension of the holistic coupling with the background that usually gives meaning to our actions, while for cognitivist Al systems this holistic direct coupling is structurally missing due to the system's lack of thrownness (see above). And that is why, when the human agent forgets about the network of endless open questions in which it is trapped in Angst, it buries the fundamental sense of uncanniness under its habitual commerce with worldly things, and becomes 'tranquillized': it can then go back to its skilled coping with the world, reactivating its background coping, a possibility that is fundamentally unavailable to machines that lack thrownness.

\section{Utilization Behaviour Revisited}

As a bonus to the main business of this paper, our analysis of ground-level intelligence has left us in a position to counter Rietveld's arguments against the distinction between intracontext and inter-context sensitivity to relevance. In particular, as far as we can tell, the phenomenon of utilization behaviour doesn't undermine this distinction, but rather demonstrates that the human capacity to produce appropriate actions is severely disrupted when the boundary in question collapses, allowing any local solicitation to acquire the role of a global precondition. The patient exhibiting utilization behaviour has not lost his sensitivity to the holistic meaning of his actions (he has a background, and he is still a thrown agent, in Heidegger's sense); the problem is that this meaning is now totally absorbed by the contingent situation. He can still perfectly cope with beds to be made, and this means that he knows the normative preconditions of this action, but he can't separate the contingent contextual solicitations from the 
holistic consideration of the whole situation, as if the bed was the totality of the world with which he must deal.

Normally, the background of our actions is not given to us as an all-encompassing and all-determining universal structure, but is articulated perspectivally within the local contexts in which it may be involved. Just as the veins in a not-yet-sculpted piece of marble suggested to Michelangelo the forms to be carved out from it, Signs delineate the different contextual articulations that a situated agent will produce by addressing pragmatically (that is, with a specific purpose in her mind) the unitary structure of her background. Indeed, Signs testify that the distinction between different contexts of action, as well as the very distinction between local contexts and the holistic background, is ontologically grounded, even though it is virtual (embedded in possibility). The appearance of Signs delineates the phenomenological boundaries separating different contexts of action, revealing whether or not it is possible to switch between them by adopting different perspectives for accessing the background. In cases where Signs announce a relevant transition between contexts, it means that genuine ontological boundaries exist within the background.

Things are very different for patients exhibiting utilization behaviour. For them, the background is entirely explicated by the actual focus of interest, such that no other contexts are possible. The dissolution of the separation between different contexts of action is demonstrated by the fact that the patient fails to experience the Signs that usually warn us to monitor our actions as soon as we cross the borders of appropriateness. The patient fails to interpret the surprised face of his host as a sign that his actions are not appropriate in her house, because the relevant contextual borders no longer exist for him. Such borders clearly exist in normal experience, which is why we immediately respond to the presence of Duchamp's famous fountain in a museum as out-of-context. From the twentieth century, the fine arts systematically 
employed the alienating experience of out-of-context objects and events in order to produce, in observers, an active reflection on the background preconditions of their own notion of a work of art. This reflection couldn't be achieved if the observers in question were not comparing the global background of the broader situation with the local factive circumstances in which it is perspectivally disclosed. Signs help us to understand when we need to switch from one context to another to continue producing appropriate behaviour. But they also tell us when our actions are crossing contextual borders into a territory of the non-appropriateness.

What now of Rietveld's neurofunctional argument? Rietveld's overall position requires (on the philosophical level) that (1) sensitivity to background conditions is never informed by context-specific competences, and (on the neurofunctional level) that (2) sensitivity to background conditions is underpinned by brain mechanisms that globally tune the sensory systems, a process which is necessary for goal-specific motor structures (dedicated to both action execution and the understanding of affordances) to underpin context-specific competences. This picture, according to Rietveld, is confirmed by the evidence that (3) the tuning of the sensory system in accordance with the agent's contextual expectations determines the conditions under which the contributions of context-specific motor competences are relevant. While we agree with (2), we have already argued that (1) represents both an inappropriately static model of the relation between background coping and skilled coping, and a transgression of the principle of mutuality. If background coping is a unitary process, then access to it is always perspectivally oriented in accordance with the way the agent engages her local context, such that different context-specific competences can determine some of the background preconditions. For example, according to the premotor theory of attention (Rizzolatti and Craighero, 2010), the same frontal-parietal circuits that control ocular movements towards specific spatial locations actively reconfigure the attention towards the same locations in order to prime the detection of salient elements (Rizzolatti et al., 1987). In an analogous way, the 
experimental data on canonical neurons show that the same pre-motor circuits that control the execution of certain goal-specific transitive actions are recruited by the process of detection and recognition of the objects that afford those actions (Rizzolatti and Luppino, 2001). These findings suggest that spatial attention and detection of the environmental features related to the relevant context of action do not result from a dedicated control mechanism, but from the same mechanisms (corresponding to SPACs, in our hypothesis) that control the execution of the appropriate actions in those contexts: "as in the case of spatial attention eye movement preparation selects a given spatial location, the preparation of a grasping movement selects an object with specific intrinsic characteristics" (Rizzolatti and Craighero, 2010). But that means that (3) tells only one half of the neurofunctional story, because, in accordance with the principle of mutuality, the medial system that tunes our capability to pick up and interpret relevant sensory stimuli can be tuned by our motor engagement with the local context with which we are interacting.

\section{Conclusions: the King's Intelligence}

The conclusions of our analysis may be expressed as a tri-dimensional pattern of agreement and disagreement with the account of ground-level intelligence that may be extracted from the work of Dreyfus and Rietveld.

First, we agree that the background is inhabited as a unitary set of holistic conditions, but this doesn't mean that the whole network of background preconditions is always equally involved in every kind of coping, because, for each form of skilled coping, some elements or modality of background coping may exclude others. The background is a vast web of significance that implicitly underpins the mattering of things during coping, but it is a structure that we always inhabit from a situated perspective, and different profiles of the background matter in different degrees at different times. Were background knowledge always equally 
present in all its aspects, there would be no need for the disclosive function of Signs, structures that highlight the background preconditions that are most relevant in the current situation or that may potentially provide a bridge to other contexts of action.

Secondly, we agree that skilled coping, whether absorbed or minimally representational, is always underpinned by background coping, but, on the basis of the principle of mutuality, we recognize that the background can in turn be modified by ongoing, concrete acts of skilled coping. The background provides an ontological platform for our situated experience, but not as an immobile ground providing an ultimate, self-sufficient, autonomous foundation, like the set of basic axioms for a formal system of first-order logic. Rather, the background is a relatively stable scaffold that orients our everyday engagements within the world. Skilled coping continuously re-founds the background by dynamically modifying the normative preconditions it embodies, but that in turn provides the normative preconditions for further skilled coping. If it is correct to conceptualize the background as foundational at all, then, as Heidegger argues, it should be characterized as a bottomless abyss of preconditions, each of which requires others, according to the general schema of the hermeneutic circle.

Finally, we agree that background coping is not guided by full-blooded representations of a traditional kind, because the background can't be reduced to a body (however vast) of explicitly represented information, beliefs, or stored heuristics. That said, we have argued that our access to the background is often mediated and articulated by action-oriented representations, sometimes appearing in our experience as Signs. This means that, in the 'right' circumstances, the production of the wrong syllable by a stuttering speaker or an unexpected road sign appearing in front of the driver can prompt a global reconfiguration of the background. So, in the end, it is a minimally representationalist approach to intelligence that brings the background and its dynamics into proper view. The problem of relevance indicates that 
background coping cannot be understood on the cognitivist model, as a rational process of deliberation using full-blooded representations. But, as we have argued, neither can background coping be understood, or at least not exhaustively so, on a Dreyfusian model, as the unreflective and nonrepresentational selection of past contexts. In other words, at ground-level, the King's intelligence, like yours and like ours, is in part a matter of negotiating the dynamics of the background by way of action-oriented representations.

\section{Acknowledgments}

Some sections include short passages of text adapted from Wheeler (2010), and Wheeler and Di Paolo (forthcoming).

\section{References}

Cappuccio, M. and M. Wheeler (2010) 'When the twain meet: Could the study of mind be a meeting of minds?' in J. Reynolds, J. Chase, J. Williams, and E. Mares (eds.) Postanalytic and Metacontinental: Crossing Philosophical Divides (London: Continuum).

Dreyfus, H. L. (1992) What Computers Still Can't Do: A Critique of Artificial Reason (Cambridge, MA: MIT Press).

Dreyfus, H. L. (2000) 'How Heidegger defends the possibility of a correspondence theory of truth with respect to the entities of natural science' in T. R. Schatzki, K. K. Cetina, and E. von Savigny (eds.) The Practice Turn in Contemporary Theory (New York: Routledge), 151-62. 
Dreyfus, H. L. (2002a) 'Intelligence without representation: Merleau-Ponty's critique of mental representation', Phenomenology and the Cognitive Sciences, 1, 367-83.

Dreyfus, H. L. (2002b) 'Refocusing the question: Can there be skillful coping without propositional representations or brain representations?', Phenomenology and the Cognitive Sciences 1(4): 41325.

Dreyfus, H. L. (2008) 'Why Heideggerian Al failed and how fixing it would require making it more Heideggerian', in P. Husbands, O. Holland, and M. Wheeler (eds) The Mechanical Mind in History (Cambridge, MA: MIT Press): 331-71.

Freeman, W. (2000) How Brains Make Up Their Minds (New York: Columbia University Press).

Gallagher, S. (2008) 'Are minimal representations still representations?', International Journal of Philosophical Studies, 16/3, 351-69.

Heidegger, M. (1996) Being and Time, John Stambaugh (trans.) (Albany: State University of New York Press). Originally published as (1927) Sein und Zeit (Tübingen: Max Niemeyer Verlag).

Kelly, S. D. (2000) 'Grasping at straws: Motor intentionality and the cognitive science of skillful action' in M. Wrathall and J. Malpas (eds.) Essays in Honor of Hubert Dreyfus, Vol. II. (Cambridge, MA: MIT Press), 161-77.

Kelly, S. D. (2002) 'Merleau-Ponty on the body: The logic of motor intentional activity', Ratio-New Series 15(4), 376-91.

Kiverstein J. (forthcoming) 'Introduction', in J. Kiverstein and M. Wheeler (eds.) Heidegger and Cognitive Science (Basingstoke: Palgrave-Macmillan).

Lhermitte, F. (1986) 'Human autonomy and the frontal lobes. Part II: Patient behavior in complex and social situations: The «environmental dependency syndrome»', Annals of Neurology, 19, 335-343.

Logue, M. and P. Conradi (2010) The King's Speech (London: Quercus).

Mataric, M. (1991) 'Navigating with a rat brain: A neurobiologically inspired model for robot spatial representation' in J.-A. Meyer and S. Wilson (eds.) From Animals to Animats: Proceedings of the First International Conference on Simulation of Adaptive Behavior, (Cambridge, MA: MIT Press), 169-75.

Merleau-Ponty M. (1962) Phenomenology of Perception, C. Smith (trans.) (London: Routledge). 
Rietveld, E. (2008) 'Situated normativity: The normative aspect of embodied cognition in unreflective action', Mind, 117/ 468, October.

Rietveld E. (forthcoming) 'Context-switching and responsiveness to real relevance' in J. Kiverstein and M. Wheeler (eds.) Heidegger and Cognitive Science (Basingstoke: Palgrave-Macmillan).

Rizzolatti, G. and L. Craighero (2010) 'Premotor theory of attention', Scholarpedia, 5(1), 6311.

Rizzolatti, G. and G. Luppino (2001) 'The cortical motor system', Neuron, 31, 889-901.

Rizzolatti, G., L. L. Riggio, I. Dascola, and C. Umiltá (1987) 'Reorienting attention across the horizontal and vertical meridians: evidence in favor of a premotor theory of attention', Neuropsychologia, 25, $31-40$.

Sutton, J. (2007) 'Batting, habit, and memory: The embodied mind and the nature of skill', Sport in Society, 10(5), 763-86.

Taylor, C. (1993) 'Engaged agency and background in Heidegger' in C. B. Guignon (ed.) The Cambridge Companion to Heidegger (New York: Cambridge University Press), 317-36.

Wheeler, M. (2005) Reconstructing the Cognitive World: The Next Step (Cambridge, MA: MIT Press).

Wheeler, M. (2008) 'Cognition in context: Phenomenology, situated robotics and the frame problem', International Journal of Philosophical Studies, 16(3), 323-49.

Wheeler, M. (2010) ‘The Problem of Representation' in S. Gallagher and D. Schmicking (eds.) Handbook of Phenomenology and Cognitive Science (Berlin: Springer), 319-36.

Wheeler, M. and di Paolo E. (forthcoming) 'Existentialism and cognitive science' in J. Reynolds, A. Woodward, and F. Joseph (eds.) Continuum Companion to Existentialism (London: Continuum). 